\title{
Diagnostic Dilemmas Associated with Bipolar Disorder After Traumatic Brain Injury
}

To the Editor:

October 18, 2008

Our understanding of bipolar spectrum disorders, including the boundaries or comorbidity of the disorder, as well as the biological factors contributing to its presentation, has evolved over time. ' An interrelationship between the behavioral and psychological symptoms of dementia and bipolar disorder has recently been proposed, highlighting the presence of potential psychiatric and neurologic comorbidity. ${ }^{2}$ Clearly cognitive impairment, behavioral difficulties, and emotional changes associated with neurological damage can potentially overlap with or mimic psychiatric diagnoses, including bipolar disorder.

Traumatic brain injury (TBI) is one of the most common causes of disability in young adults. Severe TBI almost inevitably results in a rather predictable combination of cognitive impairment, emotional difficulties, behavioral change and, in many cases, poor self-awareness or insight. ${ }^{3}$ Common symptoms include irritability, poor attention, impulsivity, sexual disinhibition and impaired memory. Almost any psychiatric diagnosis can present for the first time after TBI. Furthermore, in many cases, pre-existing psychiatric problems can be accentuated by TBI. Depression and a range of anxiety disorders are particularly common after TBI. Bipolar disorder is perhaps one of the less frequently encountered new-onset mood disorders associated with a history of TBI.

A history of TBI appears to increase by 1.5 times the chances of developing bipolar disorder. ${ }^{4}$ Mania secondary to TBI has been reported in up to $9 \%$ of patients, ${ }^{5}$ however, a review of five studies found a lower prevalence of $4 \% .^{6}$

While bipolar disorder is not as common as other mood disorders or anxiety disorders after TBI, it is nevertheless a potential psychiatric complication of TBI. Furthermore, bipolar disorder can pose considerable diagnostic challenges in a patient with a history of severe TBI. Two main difficulties arise in this situation. Disentangling symptoms common to both TBI and bipolar disorder and identifying the contribution of biological and non-biological factors underlying the presentation.

The neurologic factors contributing to bipolar disorder after TBI remains unclear. A potential coexistence between secondary mania and posttraumatic epilepsy has been suggested ${ }^{7}$ while others have reported left fronto-parietal haemorrhage $^{8}$ or bilateral temporal lesions ${ }^{9}$ or temporal basal polar lesions in patients with bipolar spectrum disorder and TBI. ${ }^{5}$ In patients with bipolar disorder in the absence of TBI, a recent review of functional imaging studies proposed that networks fundamental to cognitive and emotional processing, the limbic, sub-cortical and frontal regions, were involved. ${ }^{10}$

Clearly, the pathophysiology associated with TBI has the potential to disrupt these networks. Nevertheless, factors other than biological are likely to contribute to personality, behavioral or emotional changes after TBI also, including loss of role, disturbed family or marital relations, and changes in personal identity. These need to be considered as potential contributory factors also, especially when a significant period of time since injury has elapsed.

Clinicians need to be aware of the possibility of bipolar disorder presenting after head trauma. ${ }^{9}$ However, making this diagnosis in the presence of TBI is complex. Many of the common symptoms of TBI, especially personality changes, such as impulsivity or sexual disinhibition, cognitive impairment related to poor attention and emotional difficulties, including irritability, can mimic the common symptoms of bipolar disorder. Perhaps one of the most pragmatic approaches then to disentangle symptomatolgy is to obtain a collateral, longitudinal 


\title{
Communique
}

history from a relative of the patient. ${ }^{8}$ In some cases neuropsychological testing can help identify potential cognitive impairment mirroring some of the symptoms of bipolar disorder. However, where a new-onset change from usual post-TBI behavioral patterns is confirmed, including a cyclical pattern of mood disturbance, the index of suspicion for bipolar disorder should be raised. Where bipolar disorder was identified secondary to TBI, some authors have suggested treatment strategies including mood-stabilizing medication, family support, and maintaining the patient's routines ${ }^{8}$ or atypical antipsychotic medicaton, ${ }^{11}$ bipolar disorder remains an under-researched, poorly understood clinical presentation after TBI that clinicians need to be aware of.

Sincerely,

Rudi Coetzer, D Clin Psy, CPsychol

\section{REFERENCES}

1. Hollander, E. New insights into bipolar disorder. CNS Spectr. 2008;13:743.

2. Dorey J-M, Beauchet $\mathrm{O}$, Anterion $\mathrm{C}$, et al. Behavioral and psychological symptoms of dementia and bipolar spectrum disorders: review of the evidence of a relationship and treatment implications. CNS Spectr. 2008;13:796-803.
3. Lezak MD, Howieson DB, Loring DW. Neuropsychological Assessment. 4th ed. New York, NY: Oxford University Press; 2004.

4. Mortensen PB, Mors 0 , Frydenberg M, Ewald $\mathrm{H}$. Head Injury as a risk factor for bipolar affective disorder. J Affect Disord. 2003;76:79-83.

5. Jorge RE, Robinson RG, Starkstein SE, et al. Secondary mania following traumatic brain injury. Am J Psychiatry. 1993;150:916-921.

6. Van Reekum R, Cohen T, Wong J. Can traumatic brain injury cause psychiatric disorders? J Neuropsychiatry Clin Neurosci. 2000;12:316-327.

7. Shukla S, Cook BL, Mukherjee S, et al. Mania following head trauma. Am J Psychiatry. 1987:144:93-96.

8. Handel SF, Ovitt L, Spiro JR, Rao V. Affective disorder and personality change in a patient with traumatic brain injury. Psychosomatics. 2007;48:67-70.

9. Mustafa B, Evrim 0, Sari A. Secondary mania following traumatic brain injury. $J$ Neuropsychiatry Clin Neurosci. 2005;17:122-124.

10. Yurgelun-Todd DA, Ross AJ. Functional magnetic resonance imaging studies in bipolar disorder. CNS Spectr. 2006;11:287-297

11. Oster TJ, Anderson CA, Filley CM, Wortzel HS, Arciniegas, DB. Quetiapine for mania due to traumatic brain injury. CNS Spectr. 2007:12:764-769.

Dr. Coetzer is a consultant neuropsychologist and head of the North Wales Brain Injury Service, North Wales NHS Trust, at Colwyn Bay Hospital in the United Kingdom and an honorary lecturer at Bangor University, United Kingdom.

Disclosure: Dr. Coetzer does not have an affiliation with or financial interest in any organization that might pose a conflict of interest.

Please e-mail letters to the editor to: V」@mblcommunications.com.

\section{Now Available at www.cnsspectrums.com}

\section{An Expert Panel Review of Clinical Challenges in Psychiatry}

\section{BEST PRACTICES IN ADULT ADHD}

Part 1: Epidemiology, Impairments, and Differential Diagnosis Part 2: Neurobiology, Pharmacology, and Emerging Treatments Part 3: Special Considerations

\author{
By Lenard A. Adler, MD \\ Thomas J. Spencer, MD \\ Mark A. Stein, PhD \\ Jeffrey H. Newcorn, MD
}

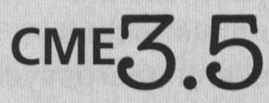

To request a published supplement, please e-mailks@mblcommunications.com

Supported by an educational grant from Shire Pharmaceuticals Inc. 